scien do Zagreb International Review of Economics \& Business, Vol. 22, Special Conference Issue, pp. 55-72, 2019

(C) 2019 Faculty of Economics and Business, University of Zagreb and De Gruyter Open

All rights reserved. Printed in Croatia

ISSN 1331-5609; UDC: $33+65$

DOI: 10.2478 /zireb-2019-0027

CONFERENCE PAPER

\title{
Can Evaluation Trigger Change? The Case of the Interim Evaluation of the Croatian Tourism Development Strategy
}

\author{
Sanja Malekovic* \\ Sanja Tišma* \\ Daniela Angelina Jelinčić* \\ Ana-Maria Boromisa*
}

\begin{abstract}
The paper is focused on the results of the first conducted sectoral interim evaluation in Croatia, that of the Croatian Tourism Development Strategy till 2020. The authors reflect on the methodology used, the applied approach, the objectives and scope of the recently implemented interim evaluation of the mentioned Strategy. They comment on the purpose and functions of this sectoral evaluation and observe objectively its role from the point of view of achieving effectiveness, long term, and concrete and sustainable development impacts in the sector of tourism. The main findings of the conducted evaluation are presented, based on a number of held interviews and a survey with the main policy makers, civil servants as well as all key stakeholders in the tourism industry. Particular focus is given to evaluation questions and judgement criteria based on the evaluation criteria of effectiveness, impact and sustainability. The authors indicate some of the positive achievements, and particularly the current problems and challenges in the segment of tourism in Croatia in the period until 2020 and beyond. Along with observations related to the issues of accountability in the sector, the paper also provides reflections on the learning effects as the end result of such an evaluation, contributing to further policy development and policy learning in the sector of tourism. The authors indicate that their experience with this first interim evaluation could serve as a good practice example for conducting similar sectoral evaluations in Croatia as well as a tool for further long term development of tourism in the country, since the sector is of pivotal importance for Croatia's local, regional and urban development as well as its overall economic competitiveness. Particular attention is given to some of the noted deficiencies and needs for further improvements in this sector, vital for Croatia's further development. Recommendations are provided for improvements of the overall Croatian tourism development policy, with specific focus on the effectiveness of the so far achieved results as well as sustainable implementation of the Strategy and overall policy, aiming at reaching major and more concrete development impacts in the field of tourism.
\end{abstract}

Keywords: interim evaluation of a strategic program; tourism policy

JEL Classification: Z32, Z38

\footnotetext{
* Sanja Maleković, Sanja Tišma, Daniela Angelina Jelinčić and Ana-Maria Boromisa are at the Institute for Development and International Relations, Zagreb, Croatia.
} 


\section{Introduction}

Tourism is still considered as one of the most relevant economic sectors, widely recognized as a relevant factor not only for achieving competitiveness on the national level, but also as an important factor in regional development (EC, 2010). By nature the tourism industry has an irreplaceable role in regional policy in most EU Member States and contributes to local and regional development due to its positive multiplier effect which triggers new business opportunities in a wide range of activities, thus significantly influencing growth, stability of local and regional economies, new employment opportunities, overall attractiveness and living conditions on the local and regional level. (Lusticky, Bina and Musil, 2015; Sharma, 2004; Downes and Rooney, 1999, Cooper et al., 2008). The benefits which are in the initial period reflected in the local communities translate in a longer term period into new investments and growth, with its positive effects on regional, and, consequently, national competitiveness.

The tourism industry is particularly relevant for Croatian local, urban and regional development, with its noticeable impact on raising the living standard and quality of life in local communities dependent on revenues from tourism. Due to its linkage as well as notable impact on other development policies, its major contribution to the overall national competitiveness is also not surprising, among them, particularly its contribution to agriculture, culture, environment, transport, leisure and other. Having this in mind, the main strategic document related to the tourism industry is a relevant starting point for continuous promotion of developmental change in a sector of key importance for Croatia's overall development.

This paper presents research findings as the result of the implemented interim evaluation of the Croatian Tourism Development Strategy till 2020 (hereinafter: Strategy), released by the Ministry of Tourism in 2013. The Strategy was evaluated in the course of its implementation ${ }^{1}$, serving as a tool for the overall improvement of the tourism policy.

The Strategy is based on the analysis of key indicators of achieved development in the tourism industry. It focuses on the development constraints but also the emerging potential, stemming from the globally relevant development trends, and indicates the key success factors which the Croatian tourism policy should employ until 2020. It must be noted though that Croatian tourism is still facing a number of serious constraints, among them, the insufficient distinction of products and services, the lack of innovative and high quality tourism facilities, growth based on the expansion of private households accommodation, the lack of high quality hotel services, unsatisfactory air and maritime traffic networks, a static system of national marketing, the lack of globally branded destinations, inadequate tourism infrastructure of a destination and the inherited inclination of the local population towards seasonal business. These pertaining weaknesses stress the importance of sound strategic programs, as well as the importance of evaluation of their implementation. The quality of strategic 
planning can be considered as one of the most relevant factors of competitiveness of tourism destinations (Lusticky, Bina, Musil, 2015), influencing by large continuous improvement and change of this policy, which is particularly relevant for Croatia.

The paper provides an overview of the purpose and goals of the conducted evaluation of the tourism policy. The overview is followed by the methodological framework used for the implementation of the evaluation, along with the key findings according to the main criteria of interim evaluation. Finally, conclusions and recommendations for further development of the Croatian tourism policy in the forthcoming period are provided.

\section{Purpose and Goals of Evaluating the Tourism Development Strategy}

Evaluation implies the obtaining, analysis and use of data aimed at improvement in the process of developing or implementing a strategic program. Primarily, efficient and timely management, decision making, education of stakeholders and responsibility for resource use and achievement of results are encouraged (Maleković, Tišma, 2011).

Evaluation can be defined as a selective exercise that attempts to systematically and objectively assess progress towards the achievement of an outcome. It involves the assessments of different scope and depth carried out at different stages in time in response to evolving needs for evaluative knowledge and learning during the effort to achieve an outcome. The focus of such an exercise is on expected and achieved accomplishments, and most particularly on determining the relevance, impact, effectiveness, efficiency and sustainability of the interventions (Smith, 2007). In this regard, its main purpose is to understand why and to what extent intended, but also the unintended results are achieved. Likewise, from point of view of the topic of our paper, it is a relevant source of evidence on the achievement of results and overall performance, improving thus the implementation of a programme and enabling the process of learning from past successes as well as failures (Maleković, Tišma, 2011; OECD, 2012). It needs to be noted however that evaluation practice cannot be perceived as purely scientific research, as if often the case. Rather, the main challenge is to produce directly useful knowledge that is of value to society. From this point of view, it can be looked upon as a form of participation in the European knowledge based society (Basle, 2006).

If we agree that the moving force behind evaluation activities is very often the desire to have a positive influence on policy, then we can also agree that one of the main goals of evaluation is to upgrade the current as well as future development policy by way of the assessment of the results of particular interventions, to enable transparency and mentioned accountability when reporting on the results of development activities, as well as to improve the management of socio-economic programmes. 
In this regard, evaluation can be perceived as a management tool, formalizing thus some of the good practice which is currently emerging on an informal basis in the framework of Cohesion policy evaluation, all of which is very relevant for Croatia's policy development and change (Maleković, Tišma, 2011). Barca is right in observing that policy makers will perceive evaluation as necessary and relevant if evaluation assessments are turned into clear-cut public messages for policy makers, and if the policy-makers are required by partners to respond with information that only evaluation can provide (Barca, 2006).

Since our research herewith is related to the first conducted sectoral interim evaluation in Croatia, it is necessary to point out that the further introduction and capacity building for evaluation in Croatia is relevant due to a number of reasons, such as (OECD, 2012; WB , 2010, Maleković, Tišma 2011., Puljiz, Maleković, Keser, 2019; EC 2013; EC 2013a; EC 2014):

- ensuring transparency, efficient and effective management of development programs

- ensuring financial and other accountability of the programme managers

- ensuring maximum return of invested resources for development programmes

- ensuring maximum long term, sustainable and relevant socio-economic development impacts for the development of certain Croatian regions

- serving as a tool for triggering public policy development and developmental change $^{2}$

- providing the means for introducing new forms of governance and enhancing an integrated approach to development.

There are additional reasons for evaluating the tourism policy, among which the following merit to be singled out (OECD LEED 2010; OECD 2012):

- to ensure full integration of tourism in the overall development strategy and the incorporation of tourism goals in other related development strategies (regional and other sectoral strategies)

- to enable greater awareness and participation - among local public and private decision makers as well as amongst the wider public, on the importance of development of sustainable tourism

- to help policy makers better assess the impacts of the tourism policy and programmes against their objectives

- to allow better cross-government understanding of the efficiency of the overall government approach in tourism on all levels

When considering the purpose of evaluation, it is hard to refrain from referring to the present imbalance between financial/procedural and outcome/performance accountability, as well as accountability and effectiveness, with administrative actions being too focused on inputs and processes, on financial and procedural accountability (Polverari, 2011). These issues are also extensively discussed in the framework of the EU Cohesion policy and Croatia is among those countries whose management of 
Cohesion policy is by far too overburdened with procedural accountability with visible unfavorable effects on impacts of implemented programmes (Puljiz, Maleković, Keser, 2019).

This interim evaluation, the first sectoral one implemented in Croatia, along with the first interim programme evaluations which are currently under way ${ }^{3}$, are by all means an opportunity for considering shifts of approach which will inevitably have to take place in the post 2020 programming period. This is of utmost importance since evaluation is still not perceived by most Croatian stakeholders as a challenge in providing useful knowledge of value to society. Suboptimal recognition of the importance of evaluation is observed on the whole and most policy makers do not consider it as a management tool and means for improving governance.

The objectives of our research stem from the main purpose of evaluation of public development policies. In this regard, and having in mind that such sectoral evaluations have not been conducted in Croatia so far, one of the prior goals of the research was to raise understanding and capacity related to the purpose and relevance of mid-term evaluation as a valuable tool for public policy evaluation in Croatia. Among other research objectives were the following:

- to demonstrate to what extent have the set goals of the Strategy been fulfilled, in line with the mentioned evaluation criteria;

- to identify the main problems and constraints for more effective implementation of the Strategy and the reaching of relevant and sustainable impacts of the policy;

- based on the conducted analysis and research findings, to provide recommendations for overcoming the main constraints and for promoting change and improvement of the implementation of the Strategy as well as the overall tourism policy;

- to point to the new emerging themes which directly or indirectly affect tourism industry, among them, sustainable tourism, safe tourism and migration.

\section{Methodological Framework for the Implementation of the Evaluation}

Interim evaluations are carried out in the course of the implementation of a strategic programme and indicate whether it is necessary to redirect and/or make corrections in the current programming period (Vidueira, Rivera, Mesa and Diaz-Puente, 2014). This was one of the goals for setting the methodological framework for this interim evaluation.

Along with the desk research of all available internal documents ${ }^{4}$, which constitutes an integral part of every evaluation, interviews have been conducted with 40 key stakeholders in the tourism industry. A thorough plan of stakeholders and public servants to be interviewed was agreed upon jointly with the core team of the Ministry in charge of following the project's implementation. It was agreed that all main stakeholders in charge of implementing the action plans as set by the Strategy 
would be interviewed with the aim of assessing their achievements. Among them were directors of the Croatian Tourist Association, and other related associations (golf, cycling, cruising, camping, other ), representatives of the Association of Tourist Guides, the Croatian Chamber of Economy, directors of hotels and associations of congress tours, the National Association of Family and Small Hotels, the Association of Rural Tourism, the Institute of Tourism, the Association of Catering and Tourism, the Association of Seascapes, the Association of Divers as well as the Association of Adventure Tourism, the Association of Cultural Tourism, tourism related private firms and numerous other. From the mentioned it is visible that the representatives of special interest tourism, which are becoming all the more relevant, were also well covered. On the whole, particular attention was given to the participatory approach, the reason why the interviewed covered the public and the private sector as well as the civil society.

With the aim of assessing the relevance and effectiveness of the implementation of the Strategy in the considered period, as well as the possibilities for achieving sustainable impacts, interviews were also held with 15 public servants of the Ministry of Tourism, responsible for the management and coordination of the implementation of the Strategy. Surveys have also been conducted among key public servants and policy makers from the Ministry of Tourism and particular focus was given to their views and recommendations for the development of the policy in the post 2020 period.

A number of the proposed criteria typical for interim evaluations have been used in order to provide the Ministry of Tourism all the basic information and findings which would help them understand the state of affairs as well as to define the optimal further steps for the implementation of the Strategy.

The basic criteria used were:

- Relevance: examines whether the aims and priorities of the Strategy are based on objective needs and development potential, i.e. to assess the degree in which the aims are justified by the needs. The main evaluation questions were the following: to what extent are the goals of the Strategy justified as compared to the needs? Are the goals in line with local, national and European priorities?

- Effectiveness: compares the achieved results with respect to the proposed measures (to which degree have the aims been reached or to which degree they are expected to be reached). The main evaluation questions were: to what extent have the goals of the Strategy been achieved? Have the used interventions and instruments produced the expected results? Would more results have been achieved if different instruments had been used?

- Sustainability: assesses if the effects of the intervention will last after its implementation, and in which degree, i.e., it examines whether the results, including institutional changes, can be assessed as permanent. The main evaluation questions were: Will the results and impacts, including institutional changes, last? Will the impact last even if the public financing ceases? What long-term (development) impacts are envisaged? 
- Impact: assesses the degree of change that can be objectively justified by the intervention. ${ }^{5}$ The main evaluation questions were: What is the contribution to the general goals of the Strategy? What are the defined monitoring indicators? What have been the intended/expected, but also the unexpected positive/negative contributions of the Strategy?

Along with the mentioned obligatory criteria, consideration in interviews and the conducted survey was also given to additional evaluation criteria such as usefulness, complementarity of measures and equal opportunities. The complementarity criteria is of particular importance when considering the integrated and sustainable development approach, not only of measures envisaged within the Strategy but also in regard to some relevant measures which are currently implemented in the framework of other related strategic documents in Croatia ${ }^{6}$.

The implementation of the Strategy according to the mentioned criteria was assessed also by way of applying a number of additional specific judgement criteria, aiming at obtaining as wide and in depth an overview as possible as well as additional useful inputs for evaluation findings and recommendations. The judgment criteria were particularly helpful in the course of drafting questionnaires for surveys.

Following the explanation regarding the use of the criteria of efficiency, it must be noted that quantitative methods were not used in the implemented analysis and research since the research team used the mentioned Report on Audit of Efficiency of the Implemented Measures Defined by the Strategy for the Development of Tourism of the Republic of Croatia Until 2020 which provided the basis for the quantitative data. The research herewith was thus based on semi structured interviews held in the period September 18th - November 6th 2017 as well as on the survey conducted in the course of November 2017.

Along with the applied criteria and evaluation tools, as well as the desk research of all available relevant documents provided by the Ministry, the aim of research was also to analyse similar strategic documents and other literature, including the implemented evaluations in other countries. Along with the referred to literature under the previous heading, among the more relevant ones were the Tourism Policy and Planning - Yesterday, Today and Tomorrow (Edgell et al, 2008), which provided a much wider development perspective on the industry in a number of countries world wide ${ }^{7}$ as well as a thorough insight on new policy issues and development themes in the industry. The Tourism Trends and Policies, (OECD, 2012) provide evidence on good governance practices which can facilitate an integrated approach to tourism which is particularly missing in Croatia, the consequences of which are multifold. The OECD LEED Policy Review on "Sustainable Tourism and Local Development in Apulia Region (2010) indicated best practice examples on the evaluation framework for tourism development not only in Apulia but also other EU regions, with focus on challenges and requirements related to seasonal tourism, retaining of seasonal workers and their integration in the local community, government measures related to education and 
training in a number of countries and other. Furthermore, from point of view of circumstances in Croatia, and some similarities in challenges and tourism development goals, insight into the Assessment of the National Tourism Development Strategy - Poland, was also useful (Sliwa-Martinez, 2012), particularly related to the sustainable development principles, and environmental management as well as the creation of ecological awareness through tourism.

As to the main limitations for the conducted research, they were analyzed and discussed with the project team and the involved staff from the Ministry in the initial period of the project's implementation. Among the most pressing limitations were poor information flow and lack of information and knowledge among some of the stakeholders related to the content and scope of the Strategy. A further limitation was the initial lack of knowledge on the goals and purpose of interim programme evaluation. This was particularly the case with the interviewed from the private sector and civil society as well as with some of the more relevant stakeholders. Both limitations were carefully considered and the project team envisaged shorter presentations on the purpose and relevance of evaluation with the aim of raising the understanding and related knowledge of the key stakeholders as well as civil servants from the Ministry. As to the lack of information on the Strategy, discussions were held prior to the interviews in order to enable the necessary understanding of all interviewed as to the strategic planning process in the Ministry and its relevance for further development of the tourism policy.

The mentioned limitations were highly considered in order to overcome the present lack of knowledge and skills and one of the contributions of the conducted research was the visible raised awareness and understanding of the goals and purpose of strategic planning as well as of evaluation of the tourism policy in the mid-term period. The key related staff of the Ministry was included in the whole evaluation process, eagerly participated at all discussions, interviews and presentations with the aim of raising their overall knowledge related to the use of evaluation for the purpose of initiating policy development and change of the current Croatian tourism policy. This fact confirmed additionally the high ownership and demonstrated accountability of the engaged policy makers and staff from the Ministry in regard to the overall assignment. Furthermore, an integral part of the implemented research was to raise consciousness of the importance of the evaluation and to convey the knowledge on its purpose and aims to the key stakeholders also.

\section{Evaluation Findings}

Following the research objectives as indicated in Chapter 2, on the basis of the used methods and evaluation tools, as well as the mentioned evaluation criteria, this Chapter provides evidence based on the conducted research. 
Taking into account the existing restrictive factors of the future development of tourism in Croatia, as well as the leading global trends in tourism demand, the implemented evaluation of the Strategy was undoubtedly focused on the prospects for reaching the goals set by the Strategy. The main goal of Croatian tourism until 2020 is to increase its attractiveness and competitiveness, aiming to position Croatia in the top 20 tourist destinations in the world ${ }^{8}$. Simultaneously, the Strategy defines the following four strategic goals of the Croatian tourism development until 2020 which were one of the key issues in the course of evaluating the Strategy:

- Accommodation structure and quality enhancement (i.e. a continuous increase of hotel accommodation, increase of the quality and decrease of the quantity in camping and household accommodation)

- New jobs creation (between 20 and 22 thousand new jobs in tourism and around 10 thousand jobs in non-tourism related services, induced by tourism)

- Investments (implementation of the new investment projects amounting to around 7 billion euros)

- An increase of tourism revenue (the overall annual revenue from the tourism industry should amount to approximately 14.3 billion euros).

\section{Relevance of the Strategy}

The first and most important goal of the Strategy - accommodation structure and quality improvement - has not been achieved so far. Even though the overall accommodation capacity has increased, the private accommodation capacity increase is significantly higher in comparison to the increase of the hotel accommodation.

Regarding new job creation, it is necessary to point out a slight upward trend in the number of employees in the tourism industry. Data from 2017 records 35.183 seasonal workers. A deficiency of skilled employees is related to the decreasing number of students finishing high schools specialized in tourism careers. A lack of knowledgeable staff in highly qualified managing positions presents an additional problem. Considering the current needs, this goal is also highly important for the remaining period covered by the Strategy.

The goal to increase investments has also not been met. Regardless of the mentioned needs and constraints, there are still no significant investments in tourism infrastructure such as golf courses, amusement parks, theme parks, visitor centers, congress centers, et al., which are mandatory for creating the necessary supply for extending the season. The Ministry of Tourism, in cooperation with the Ministry of State Property and the Agency for Investments and Competitiveness, has issued the Investment Projects Catalogue, which yielded a launch of some investments, basically brownfield ones. However, there are no greenfield investments which would significantly extend the season, and, consequently, increase the tourism revenue. 
Finally, the increase of tourism revenue is going in the opposite direction. Even though the increase of visitor expenditure per travel was aimed at, the foreign exchange revenue per foreign visitor is decreasing. The Strategy has foreseen the diversification of products and services (nautical, health, cultural, business, golf, cycling tourism, wine and culinary tourism, adventure and sports tourism, et al.) which could extend the season, widen the geographical base from the coast to the hinterland, and, consequently, increase the revenue. However, the prepared action plans are not being implemented. Even though some relevant actions have been initiated, aiming at the development of continental tourism, the most pressing obstacle for significant change is still the lack of accommodation facilities.

It is necessary to point out the fact that none of the strategic investment projects have been implemented between 2013 and 2017 for the purpose of achieving the aims set to increase the revenue, attractiveness, competitiveness and investments in tourism. A need for intensifying the implementation of related measures is evident if the set goals are to be reached.

The degree in which the achieved results have been reached has also been assessed, particularly from point of view of whether they have satisfied at least some of the long term pressing needs in the tourism industry.

The results of the implementation have also covered certain needs regarding the increase of the overall quality of tourism services. ${ }^{9}$ It is observed that the Strategy targets all key issues such as the transformation of the accommodation structure, the extension of the season, the supply quality increase, the inclusion of local population and the opening of small private hotels working year-round and adaptable to changes. Furthermore, key stakeholders positively assess the idea of the year-round tourism, with a particular emphasis on the development of special interest tourism (e.g. congress and health tourism, etc.). Overall, interviews with the key stakeholders and evaluation results related to this criteria confirm that the goals are relevant and have been defined well. However, the stakeholders simultaneously insist on the simplification of the implementation of the Strategy as well as on investments in employee training.

\section{Research Findings Related to the Criteria of Effectiveness}

Taking into account the degree of the goals' implementation and comparing it to the results of the Travel and Tourism Competitiveness Report from May, 2015, and May, 2017, a slight progress of the Republic of Croatia according to the criterion of competitiveness (WEF) is visible (in 2015, Croatia was in the 33rd place, and in 2017 in the $32 \mathrm{nd})^{10}$.

An expansion of provided services has also been planned, primarily regarding hotel accommodation, as well as the stagnation and decrease of the upward trend of household accommodation after 2015. Therefore, even though the planned number of beds has been reached, the household accommodation capacity should have stagnat- 
ed or exhibited a slower growth, which wasn't the case. Some of the key reasons why the strategic goals haven't been fully reached and why most of the defined measures haven't been implemented are an insufficient number of professional officials in the Ministry, insufficient financial resources and dependence on external funds, insufficiently aware and proactive stakeholders, as well as slow and inefficient inter sectoral (inter-ministerial) cooperation.

Albeit, several positive changes did occur in the tourism industry during the observed period: extension of the season, increased tourist expenditure, the increase in tourism revenue, new job creation and new investments. Numerous innovations have also been introduced, such as the eVisitor ${ }^{11}$ system. Additional positive changes include state support for small businesses in tourism and progress in family farm businesses training on rural tourism.

Some of the key restrictive factors regarding the implementation of the Strategy relate to weak inter-ministerial cooperation as well as the lack of vertical coordination of all services down to the destination level. Insufficient cooperation between the public and the private sector has also been pointed out. Some of the negative effects are the result of inadequate implementation of the measures, the lack of a sufficient number of qualified workers due to the migration of young people to the EU countries, and the failure to meet the defined increase of hotel accommodation in regard to the overall accommodation.

The views of key stakeholders reflect the fact that a major shortcoming of the Strategy implementation is the weak management and coordination of its implementation. The stakeholders consider most of the defined action plans irrelevant in the practical sense, with a lack of focus on the key measures. Among rather important issues, insufficient use of the EU funds, seasonality and an inert approach to continental tourism development were raised.

Evaluation of 'unexpected' changes which have occurred in the observed period were also considered. Among positive unexpected changes is the increase of the overall quality of supply, i.e. enhanced branding of Croatia as a recognizable and attractive destination of high quality. Consequently, this has yielded a large increase in the increase of private accommodation, which, according to stakeholders' opinion, does not generate an adequate supply of high quality, new job creation and added value. On the other hand, one of the key negative unexpected changes was the increase of VAT from $13 \%$ to $25 \%$. Moreover, the legalization of private facilities has caused the unexpected expansion of private accommodation. Since the infrastructure of the local self-government units (water supply, wastewater treatment, roads, parking, et al.) does not allow for an increase in the number of visitors, the aforementioned causes the quality of services to decrease. This issue is simultaneously related to the issue of sustainability.

Based on research findings, the issue of coordination is among the most critical ones for enhancing the effectiveness of the implementation of the Strategy. Therefore, 
it is of outmost importance to include all the key stakeholders (self-government units, Croatian Forests Ltd., Croatian Roads Ltd., Croatian Water Management Company, Croatian Railways and other), as well as to thematically ${ }^{12}$ carry out the defined actions via operational inter-departmental bodies. By reaching the aforementioned, the strategically important complementarity of the measures would be secured, i.e. the mutually supportive and synergetic effects of the measures set by the Strategy and the strategic programs from related development policies.

\section{Assessment of Impacts}

The evaluation was also focused on the possibilities for achieving the expected impacts. Most of the stakeholders have assessed the meeting of the goals set by the Strategy as an important factor for the overall economy of Croatia. Tourism is currently among the main driving forces for activities within other sectors. If the actions set by the Strategy continue to be directed in a goal-oriented and methodical manner, it is reasonable to expect an economic momentum in processing industry, food as well as other industries.

Stakeholders are aware that the rise of private accommodation contributes to meeting the defined overnight stays and enables the rise of the living standard, which assigns tourism an important role in achieving economic and social objectives. However, most of the interviewed stakeholders perceive the increase of private accommodation as potentially negative in the future, especially if not followed by the increase in the quality and the standardization of accommodation as well as the reinforcement of the necessary infrastructure services (municipal, transport, and other), which depend on the local and regional self-government units' readiness and capability.

Considering the implementation of the Strategy in terms of the realization of predicted impacts, it is obvious that this will not be easily achievable. The mentioned predicted overall tourism revenue in Croatia by 2020 should amount to 14.3 billion euros and cannot be reached since Croatia does not dispose with the necessary resources - natural and anthropogenic, as well as human - to support such rapid development.

Even though the set targets for tourist arrivals and overnight stays have been reached, this does not apply to the indicators of the quality of the provided services. The high pressure on the public and tourism infrastructure reflects a lack of the quality of tourism services during the peak season.

One of the key circumstances jeopardizing the expected impacts was the slowpaced growth of the development of continental tourism, which is unjustifiable since resources for the development of various forms of tourism do exist ${ }^{13}$. A further constraint for achieving synergic impacts in tourism is seen in poor cooperation between the local self-government units in the development of tourism products of mutual interest. No less important in this regard is a higher number of skillful and highly professional personnel, which both the Ministry and tourist boards lack. 
One of the mentioned impacts that can still not be objectively measured is the VAT rate increase, the result of which was the decrease of investments in the tourism industry. This has directly affected the decrease of the planned tourism investment increase defined by the Strategy as one of its strategic goals. Moreover, stakeholders emphasize the uncertainty of impacts of the announced property tax in tourism, which also brings long term plans for the tourism industry investments to a standstill. No less important is the stakeholders' opinion on the insufficiently addressed safety aspect of the future tourism development, which confirms a lack of analysis of the possible impacts of unwanted events on the future development of tourism in Croatia (i.e. disasters in maritime transport - cruise ships, oil tankers, terrorism, climate change, fires and similar.)....

Overall, it is possible to conclude that some of the key restrictive factors which could jeopardize the achievement of the expected development impacts of the Strategy are the following:

- High number of tourists in relation to carrying capacity, which could result in the decrease of the quality of services and impact the overall tourism revenue

- the insufficient capacity necessary for the implementation of the Strategy

- insufficiently and ambiguously defined roles of key stakeholders

- insufficient number of staff/workers (coordinators) for the realization of the defined interventions in nautical, health, cultural, congress and cycling tourism, as well as for private accommodation, entrepreneurial clusters, et al.

- a lack of competent workforce in the catering industry (departure of young people).

\section{Assessment According to the Sustainability Criteria}

During the evaluation of the Strategy, according to the sustainability criteria, it should be taken into consideration that most of the measures defined by the Strategy are still in preparatory phase and it is not possible at this stage to assess the implementation of the Strategy based on the criteria of sustainability. The results achieved so far are still subject to various circumstances, such us environmental, economic, financial, demographic, security, migration and other global policy issues.

The key stakeholders advocate the idea of sustainable tourism being the only possible option for Croatian tourism in the future, which should be driven by deliberate and joint efforts to achieve the predefined and agreed strategic goals. Stakeholders believe that it is important to achieve a general policy consensus with the purpose of ensuring that the strategic goals remain unchangeable, at least during the medium-term period, as well as to strictly define the implementation plan. However, it is necessary to increase the capacity for the implementation of the Strategy. Hereof, a lack of knowledgeable staff presents one of the key challenges for the sustainability of the Strategy. 
Another challenge for sustainability represents the infrastructure (transport, municipal, safety, environmental infrastructure, cultural and historical heritage conservation, et al.), currently insufficiently developed when considering the necessary support for further development of sustainable tourism.

Finally, it has become impossible to perceive the sustainability of the Strategy devoid of current changes in global tourism trends, such as the increased demand for vitality tourism (cycling, scuba diving, adventure tourism, open-air concerts and other), which substantially affect the increase of demand for such services in Croatia as well. A brand tracking research has indicated a significant drop in the sun and sea tourism model, and an increased demand for special interest tourism in Croatia. As was the case with the aforementioned criteria, progress will be feasible only in circumstances of following and implementing the recently achieved good practice in EU member states and other countries, as well as by way of investing in the necessary skilled personnel.

\section{Conclusions}

Even though the aims of the Strategy have been set high, they are in the midterm period nevertheless still justified and completely aligned with the national development priorities aimed at economic and social development. A notable emphasis has been put on the quality of tourism supply, the development of special interest tourism and the necessary prolongation of the season due to the extremely seasonal and cyclical nature of Croatian tourism ${ }^{14}$.

The projects that have been implemented so far prove that the available funds are used well and for the purpose of achieving the main goals of the Ministry. Although nominally small, the funds have provided the basis for the rise of awareness of local actors as to the importance of the development of specific tourism products for the purpose of broadening tourism services.

Regarding the results achieved by the implementation of the measures, a number of positive changes occurred, such being the prolongation of the season, increased consumption, increased tourism revenue, new job creation and new investments in tourism. Albeit the accomplished, and regardless of the increased consumption, overall attractiveness and competitiveness, the absence of strategic investment projects comes to the forefront in the period 2013 - 2017.

The evaluation has confirmed that the reasons behind failing to carry out the planned interventions are mostly due to the insufficient number of professional and competent staff, a lack of financial funds and dependence on the external financial sources, a lack of conscious stakeholders engaged in the implementation of specific measures and weak and inefficient inter sectoral cooperation - a particularly critical segment. It should also be noted that one of the most important circumstances where 
expected impacts have not been achieved, albeit their importance, relate to negligible change in the development of continental tourism.

Even though key stakeholders are advocating a model of sustainable tourism - in terms of quality and resources - as the future, the main factor restraining the sustainability of the Strategy in the long term period is the high number of tourists with respect to the carrying capacity, which can further lead to a decrease in the quality of services and overall revenue from tourism. The Polish experience with innovations and green infrastructure solutions in natural protected areas as well as green transport connections and environmental management, including the creation of ecological awareness through tourism (Sliva Martinez, 2012) are worth considering in this regard.

Based on the initially set research objectives, the conducted analysis and research findings, following the main evaluation criteria, it is possible to suggest a few key recommendations, i.e. activities, which could trigger an increase of effectiveness regarding the achievement of goals set by the Strategy until 2020, as well as in the course of a longer term period. Firstly, it is necessary to ensure better coordination, more efficient, effective, simplified and flexible organization as well as an improved information flow among all involved in the course of further implementation of the Strategy. The aforementioned relates to the necessity of systematic consolidation of horizontal cooperation and relations with other Ministries and related institutions with the aim of enhancing the integrated (inter sectoral) approach to development in Croatia $^{15}$, with the tourism industry having in this regard a key role as the promotor of economic development and competitiveness. It is important to underline herewith the pressing need for developing stronger cooperation with the Ministry of Culture in supporting the economic use of cultural heritage with the purpose of strengthening the sector of tourism.

Overall, new forms of governance in EU member states as well as in numerous other countries provide plentiful experience related to enhancing the strategically important cooperation and coordination in the tourism industry aimed at alleviating problems pressing further development and competitiveness of the tourism industry. Among the beyond EU experiences, which also merit attention, in this case Canada needs to be singled out with its achievements in developing coordinated approaches with a full and complementary partnership in tandem with both public and/or private sector organizations (Edgell, D. et al, 2008).

Moreover, evaluation findings have proved that it is necessary to systematically strengthen vertical cooperation with counties, cities and municipalities, and to encourage their joint cooperation on projects relevant for local and regional development. It is also particularly important to ensure the synergy of measures, activities and strategic projects by way of ensuring the coherence and complementarity with goals and priorities form other local, regional and urban strategic development programs $^{16}$. 
Furthermore, by far more attention should be given to the development of activities aimed at strengthening continental tourism ${ }^{17}$, as well as to new related policy issues and emerging themes (responsible management of sustainable tourism/sustainable ecotourism, climate change and tourism, tourism and safety, health related tourism, experience economy, special interest tourism - green, health, adrenaline, adventure, vitality, and other).

Finally, it is necessary to define Croatia's long term tourism development priorities. The 2021-2028 Strategy (in line with the forthcoming multiannual financial framework of the EU Cohesion policy) has to be defined with an emphasis on a participative approach and in compliance with new forms of governance which include not only key stakeholders and development actors of the overall tourism industry, but also citizens (their representatives) and associations.

The above mentioned appears to be feasible in circumstances of raised accountability and ownership of the key policy makers and stakeholders in regard to the main goals and expected long term and sustainable impacts of the Strategy. In this regard, the implemented evaluation project, resulting with raised awareness, understanding and knowledge related to the purpose and goals of evaluating the tourism industry, as well as knowledge related to organizational learning and the strengthening of leadership and effective implementation of the Strategy, will surely be useful in the process of promoting further positive change of the tourism policy.

\section{Acknowledgement}

The authors wish to thank the staff from the Ministry of Tourism of the Republic of Croatia for their highly committed and continuous support in the course of the implementation of the project.

\section{ENDNOTES}

\footnotetext{
${ }^{1}$ Covering the period 2014-2017

${ }^{2}$ Since it explicitly points out the results of socio-economic development of the implemented development programs and policies.

${ }^{3}$ For example, Operational Programmes, relevant for using EU funds in the 2013-2020 Cohesion Policy Multiannual Financial Framework.

${ }^{4}$ Among them, the action plans, national programs, Annual Reports on the Implementation of the Strategy, Report on Audit of Efficiency of the Implemented Measures and similar.

${ }^{5}$ The Strategy was not evaluated according to the criteria of efficiency since this evaluation aspect was undertaken in the framework of the elaborated Report on Audit of Efficiency of the Implemented Measures Defined by the Strategy for the Development of Tourism of the Republic of Croatia Until 2020
} 
${ }^{6}$ The Strategy was not evaluated according to the criteria of efficiency since this evaluation was undertaken in the framework of the elaborated Report on Audit of Efficiency of the Implemented Measures Defined by the Strategy for the Development of Tourism of the Republic of Croatia Until 2020.

${ }^{7}$ Including the USA, Canada and Asia.

${ }^{8}$ Based on the competitiveness criterion (World Economic Forum, WEF).

${ }^{9}$ For example, the period between 2014 and 2017 recorded an increase in the number of 4-stars hotels; investments aimed at raising the quality of private accommodation were made, and the state-owned tourism infrastructure issues were solved.

${ }^{10}$ http://www.konkurentnost.hr

${ }^{11}$ The activation of the eVisitor system has greatly simplified the realization of tourist check-ins and check-outs for the accommodation providers, private renters, and others. The Ministry has obtained the tools and information which could serve as an important database for monitoring the trends and upgrading everything that can be gathered from that database.

${ }^{12}$ For example, cultural, health, nautical, rural, golf, green, cycling and other tourism.

${ }^{13}$ Particularly, for example, for health tourism.

${ }^{14}$ Seasonal tourism asks for particularly tailor made measures, primely related to integrating seasonal (often migrant) workers in the local community, raising their skills and providing housing and other benefits, aiming at retaining the necessary workforce. The French experience, for example, merits attention with its measures targeting seasonal workers - from the creation of specific employment contracts for seasonal work to the development of employers' groups, provision of better access to training and recognition of acquired skills, access to housing benefits and other (OECD, LEED, 2012).

${ }^{15}$ This is especially significant with respect to agricultural, economic, environmental, cultural, and transport policies.

${ }^{16}$ This is particularly related to county development strategies, tourism development strategies of the local and regional self-government units, as well as development strategies of urban areas.

${ }^{17}$ Including agritourism, which is particularly relevant for Croatia's continental regions.

\section{REFERENCES}

Barca, F. (2006): European Union Evaluation between Myth and Reality: Reflections on the Italian Experience, Regional Studies, Routledge, Newcastle upon Tyne, Vol. 40. No.2: 273-276.

Basle, M. (2006): Strengths and Weaknesses of European Union Policy Evaluation Methods: Ex-post Evaluation of Objective 2, 1994-99, Regional Studies, Routledge, Newcastle upon Tyne, Vol. 40. No. 2: 225-235.

Cooper, C., Fletcher, J., Fyall, A., Gilbert, D., \& Wanhill, S. (2008). Tourism: Principles and Practice (4th Edition). Pearson Education, Harlow, 704.

Downes, R. \& Rooney, M.L. (1999). Wish you were here? Tourism and the Structural Funds. IQ-Net Thematic Paper 5(2). ISBN: 1-871130-23-9, 41.

European Commission (2013). EVALSED. The Resource for the Evaluation of Socio-Economic Development. Brussels. 119.

http://ec.europa.eu/regional_policy/sources/docgener/evaluation/guide/guide_evalsed.pdf

European Commission (2013a). Secretariat-General: „Public consultation on Commission Guidelines for Evaluation“, Brussels. 44. 
http://ec.europa.eu/dgs/secretariat_general/evaluation/docs/20131111_guidelines_pc_ part_i_ii_clean.pdf

EC (2014). Guidance Document on Monitoring and Evaluation, The programming Period 2014-2020. Brussels. 44.

http://ec.europa.eu/regional_policy/sources/docoffic/2014/working/wd_2014_en.pdf

EC (2019). Europe, the World's No 2 Tourist Destination - a New Political Framework for Tourism in Europe. Brussels: COM. 352.

Edgell, David L. Sr., DelMastro Allen, M., Smith, G. \& Swanson, J.R. (2008). Tourism Policy and Planning - Yesterday, Today and Tomorrow. ISBN: 978-0-7506-8557-3. http://shora.tabriz.ir/Uploads/83/cms/user/File/657/E_Book/Tourism/Tourism\%20Policy\%20And\%20Planning.pdf

Lusticky, M., Bina, V. \& Musil, M. (2015). Stakeholder Approach to Evaluation of Tourism Development Plans. Strategic Management Quarterly. 3 (3), 33-59. DOI: 10.15640/smq.v3n3a3

Luštický, M. \& Kincl, T. (2012). Tourism Destination Benchmarking: Evaluation and Selection of the Benchmarking Partners. Journal of Competitiveness, 4 (1), 99-116.

Malekovic, S., Puljiz J., \& Tišma, S. (2011). New Opportunities for Regional and Local Actors in Croatia in Supporting Socio-Economic Development. Southeastern Europe 35 (2), 168-190.

Maleković, S., \& Tišma S. (2011). Evaluating Pre Accession Assistance - Rethinking its Effectiveness in Promoting Developmental Change. 9th International Conference on Enterprise in Transition, University of Split, Bol, 90-100.

Ministry of Regional Development and EU Funds (2015). Guidance on Procedure and Methodology for Assessing Regional Development Policy. Zagreb: The Government of Croatia

Ministry of Tourism of the Republic of Croatia (2013), Croatian Tourism Development Strategy till 2020. Zagreb: The Government of the Republic of Croatia

Ministry of Foreign Affairs, France (2010), Spatial Planning and Sustainable Development Policy in France, Paris. 99.

OECD (2012). Evaluating Tourism Policies and Programmes. OECD Tourism Trends and Policies. Paris: OECD Publishing, 424.

Polverari, L. (2011). The Effectiveness of Cohesion Policy Implementation: Conflicting Accountabilities and Accountability Efficiency Trade Offs, paper presented at the conference "What Future for Cohesion Policy?, Bled. 11.

Puljiz, J., Maleković, S., \& Keser, I. (2019). Cohesion policy in Croatia: what have we accomplished so far?. In Petak, Z., \& Kotarski, K. (Ed.) Policy-Making at the European Periphery: The Case of Croatia. Palgrave Macmillan, 285-302.

Sharma, K.K. (2004). Tourism and Regional Development. New Delhi: Sarup \& Sons, 293.

Sliva_Martinez, K. (2012). Assessment of National Tourism Development Strategy - Poland, CEEweb for Biodiversity, Krakov. 29.

Smith, R.D. (2007): Monitoring and Evaluating - from inputs to results, Seminar on Cohesion, Ministry of Foreign Affairs and European Integration, Zagreb, 15.

Vidueira, P., Rivera, M., Mesa, B. \& Díaz-Puente, J.M. (2015). Mid-Term Impact Estimation on Evaluations of Rural Development Programs. Procedia - Social and Behavioral Sciences 191 (2015). 1596-1600. DOI: 10.1016/j.sbspro.2015.04.523

The World Bank (2010). Handbook on Impact Evaluation: Quantitative Methods and Practices, 262. 